\title{
Teaching Modern Standard Arabic for Non-Native Speakers as a Lingua Franca
}

\author{
Abdullah A. Jaradat* \\ Nisreen Naji Akeel Al-Khawaldeh*
}

${ }^{*}$ Dept. Of English Language and Literature, Hashemite University, Jordan

\author{
Doi:10.5901/mjss.2015.v6n5p490
}

\begin{abstract}
Most often, teaching Arabic for non-native speakers is viewed from a diglossic perspective where scholars disagree on the pros and the cons of teaching Modern Standard Arabic (MSA) i.e. the variety of Arabic mostly used among academics and in media, alone or one of the regional varieties or both. This paper calls for teaching MSA as a lingua franca i.e. a language of wider communication, since it is easily understood all over the Arab world, liberating the language from the debatable dichotomy detected in diglossia. This paper is the first in field that connects teaching a variety of Arabic with the benefits and the merits the variety might guarantee the learners in the future. The merits and the benefits as well as other arguments supporting teaching MSA include: MSA is still understood easily all over the Arab World; MSA is the variety of nobody and everybody at the same time; teaching MSA solves the dilemma of which dialect or variety to teach; MSA is the most prestigious variety of Arabic; the label given for varieties is generally an umbrella that covers different regional and social sub-dialects, teaching MSA may pave the way for further Arabic and Islamic Studies, teaching MSA will enhance job opportunity for learners in the field.
\end{abstract}

Keywords: Modern Standard Arabic, Diglossia, lingua franca, varieties, job opportunities, teaching Arabic for non-native speakers

\section{Introduction}

This paper attempts to emphasize the significance of teaching Modern Standard Arabic (MSA) for non-native speakers as a lingua franca liberating it from the dichotomous classification it is always confined to with the spoken varieties. The paper tries to present some theoretical arguments supporting teaching MSA to non-native speakers of Arabic as a target and as a medium of instruction with constant reference to one or two spoken varieties for purpose of exposing the students to the linguistic situation in the Arab World. Moreover, the paper connects the selection of a certain variety with the motives behind learning, and the future merits the learners might achieve. It is in fact the first study that connects between the teaching of an Arabic variety and the future of the learners in terms of job opportunities, pursuing study, and access to the Arab world among several other things. The paper points out that learning MSA is in fact a great asset and a major service for learners of Arabic for the various.

Welles (2004) says that according to the MLA report that from 1998 to 2002 there was a 92\% increase in the number of Arabic programs throughout the United States. Unquestionably, the heartbreaking events of 9/11 have lead to a further unmatched rise in these programs as well as the number of students enrolled in them.

Furman, Goldberg, \& Lusin (2010) in the MLA report about the year 2009 revealed a greater increase in the number of Arabic programs and students enrolled in Arabic classes. According to the report, the number of students enrolled in Arabic classes has jumped from 23,974 in 2006 to 35,083 in 2009 which represents a $46.3 \%$ increase, the highest increase percentage-wise for course enrollment for seven foreign languages (p.4). Accordingly, Arabic occupied the eighth position in the rank of the most studied languages in the US in 2009. Moreover, the increase was accompanied with a rise in the number of students enrolled in advanced classes. These changes are taking place despite the fact that, according to the MLA report, Arabic is one of the languages that "require extended learning periods for most native speakers of English" (p.5).

One major question that should be looked upon when Arabic for non-native speakers is discussed is which variety to teach. An answer to this question cannot be easily determined as there are various varieties of spoken Arabic, which may display minimal or maximal changes, as well as MSA, which is unified across all the Arab countries. All of these varieties are equally qualified to be candidates. However, due to the profusion of Arabic programs in the United States; the variation in the goals behind opening these programs; and the variation of the countries of origin of the instructors in these programs, various varieties of Arabic, including Standard Arabic have been selected to be taught. Modern Standard Arabic is still taught in most of the programs as the target language and the medium of instruction with marginal 
references to one of the regional varieties. Other programs call for starting with a regional variety for some time at the beginning and then moving to MSA to enable the students read and write. This situation has lead to heated debates between specialists and scholars in the field as to which is the most suitable path to adopt.

I claim that teaching the formal variety of Arabic or MSA, liberated from the binary or the dichotomous classification it is always confined to with the spoken variety in diglossia is of great benefit to students since, when liberated, it functions as a lingua franca or a language of wider communication between native speakers of different spoken varieties of Arabic or between native speakers and new learners of Arabic in a very similar manner to English throughout the world. In fact, I claim that teaching the spoken variety will surely cause several problems to learners of Arabic during the process of learning and in their practical life later on. In what follows, I present my viewpoint as a native speaker of one spoken variety i.e. Jordanian Arabic, and a specialist in the field.

I believe that the issue of which variety to teach should be handled in a broader context that views the general condition of MSA alongside the spoken varieties of Arabic under the sociolinguistic term diglossia. This issue is handled in section two which also talks about a very closely related issue i.e. the relationship between language and identity, and language ideologies. The paper then moves to review previous studies that have discussed the topic. It clarifies the two views mentioned above. The discussion section presents the arguments I propose in support of teaching MSA as the main medium of teaching and the targeted language of study. However, the approach I call for does not seek to exclude regional varieties from the process of teaching; rather, I call for integrating one or two of these varieties later for the aim of exposing students to the language situation in the Arab world.

The study is significant for the following reasons. First: it goes along the heated discussions taking place between specialists in the field of teaching Arabic for non-native speakers regarding which variety to teach. Second, the paper proposes a unique unprecedented view of this issue calling for liberating the dialects and the Standard variety from the diglossic dichotomy they are labeled with all the time. Third: this study distills some further momentum from the unprecedented increase in the number of Arabic learners in the United States and the world at all levels illustrating that this phenomenon is vital and viral at the same time. Fourth: it connects the selection of a variety to the future benefits learners may from learning MSA.

\section{Diglossia}

The term was first coined by Ferguson (1959) to describe a linguistic community in which two varieties of the same language are used in exclusive domains. Ferguson $(1959,1996)$ defines diglossia as follows:

Diglossia is a relatively stable situation in which, in addition to the primary dialects of the language (which may include standard or regional standards) there is a very divergent, highly codified (often grammatically more complex) superposed variety, the vehicle of a large and respected body of written literature, either of an earlier period or in another speech community, which is learned largely by formal education and is used for most written and formal spoken purposes but is not used by any sector of the community for ordinary conversation. PP 34-35.

According to the definition, one of the varieties is considered the $\mathrm{H}$ (high) variety since it is the most prestigious; the one that is codified and preserved in grammar books and dictionaries; the one with rich literary heritage; and the one that is used for administration and media. The other variety is considered the $L$ (low) variety since it lacks prestige; the one that is not codified; the one that lacks any heritage and the one that is not used for administration; it is only used for communication between people for daily functions. In addition, the $L$ variety is acquired at home as the native language of the speakers, while the $\mathrm{H}$ variety is learned later at school through study. This means that the $\mathrm{H}$ variety is not the native language of any body.

Arabic is usually given as the best example of diglossia. Arabic is said to have two levels of varieties used in parallel, but in different contexts: Modern Standard Arabic (MSA) is considered the $\mathrm{H}$ variety; and a group of regional varieties, each is used in a certain Arab country and its name is derived from the name of the country (e.g. Jordanian Arabic, Syrian Arabic, Saudi Arabic, etc). Moreover, it is best understood by the speakers of that country. These spoken varieties are acquired at home and used for communication in daily life. The MSA, on the other hand, is codified through grammar books and dictionaries, and is the prestigious variety.

When it comes to the issue of the functions served by these varieties, each of the two varieties fulfills different functions. The $\mathrm{H}$ variety, MSA in this case, is closely related to Classical Arabic (CA) which is based on the language found in the Holy Quran. Both varieties are revered and considered sacred. additionally, there is a sizable body of written literature held in high esteem expressed through the $\mathrm{H}$ variety (Van Moll, 2010). The H variety is as Palmer (2007) says, is 'mutually intelligible in the Arab World' and it is used in media, in religious programs, in Friday Prayer speeches, and in formal situations, whereas the vernacular is used in daily communication. 
Although MSA is not used for daily communication, and is restricted in the functions it fulfills, it is accessible to ordinary people, even the uneducated, since they are exposed to it on a daily basis; newspapers use MSA: news broadcasts, whether on radio or TV use MSA; religious programs and Friday congregational speeches use MSA; application forms of any type are written in MSA and finally formal situations like interviews, press releases, royal speeches, etc use MSA.

Closely related to diglossia is the issue of identity and pride. Abuhamida (1988), Suleiman (2003) and Haeri (2003) say that Pan-Arab nationalists have proposed adopting a unified Arabic language as a unifying factor for all Arabic speaking people in the Arab world. MSA, according to these scholars, is the sole candidate since it written and comprehensible to all Arabic speakers. This variety is believed to be more beautiful, more logical, and more sophisticated. Moreover, the prestigious status of Classical Arabic as an $\mathrm{H}$ variety is clearly stated in Ferguson (1996), Van Moll (2003), and Haeri (2003) among many. They claim that the prestige of this variety stems from the rich literary heritage expressed via this variety. In this context, Haeri (2003) says that ' $\mathrm{CL}$ (Classical Arabic) is a language whose aesthetic, and musical qualities move its listeners creating feelings of spirituality, nostalgia, and community (p.43)'

The spoken varieties, on the other hand, are mostly not written and they are used to perform daily functions, like shopping, commuting, repairing a car, expressing sympathy and nearly every similar daily situation in life. Due to the fact that these varieties are unwritten, and to the supremacy of MSA in all formal situations, spoken Arabic is often seen as a corruption of MSA. Moreover, each spoken variety which carries reference to the name of the country in which it is spoken, is in fact an umbrella for a continuum of regional varieties that may have minimal or maximal differences.

Vernaculars or regional varieties cannot be separated from the identity of the people speaking it. Each variety or dialect stands for or represents a unique culture and people. (Palmer, 2007 and Stadbauer, 2010). Stadbauer (2010) says that Egyptian Arabic as a vernacular cannot be separated from the identity of the Egyptian people; a generalization that applies to other vernaculars spoken in different countries. Haeri (2003:37) adds 'Egyptian Arabic is the mother tongue used for every-day communication in Egypt and serves as a marker of Egyptian identity and national culture.' Versteech (2004) says that 'the colloquial language' is closely related to in-group and solidarity, whereas Formal Arabic is related to 'distance between speakers.' Although the first part is right, I do not agree with him in the second part. I would rather consider it false since Formal Arabic as mentioned above is not used in daily communication and in its context of use is a unifying factor.

\section{Literature Review}

Scholars have taken opposing views as to which variety of Arabic should be taught in these programs. Some are calling for teaching MSA at the inaugural stages of teaching, exposing students minimally to one of the spoken varieties. 'AlKitab', the most widely used book in the United States written by notable names in the field: Kristen Brustad, Mahmoud Al-Batal, and Abbas Al-Tonsi (2004), follows this path. Other scholars are calling for teaching one of the spoken varieties at the inaugural stages of teaching moving later to MSA, claiming that this order resembles the natural order of language acquisition. In what follows, I will review the major studies that have approached this issue.

Palmer (2007) reports that according to the (2004) survey of the National Middle East Language Resource Center (NMELRC), teaching spoken Arabic is still 'the exception' in the institutions of higher education throughout the United States. This survey unmistakably proves the dominance of MSA as well as the preference of the instructors to teach it over the spoken varieties of Arabic regardless of motives and factors. He further writes that Arabic programs are established and should be prepared to train learners to communicate effectively with Arabic speaking world (p.111). In this context, Al-Batal (1995) claims that teaching Standard Arabic or what he calls the 'formal variety of Arabic' exclusively might create an unrealistic image picture of oral proficiency since learners are being taught a variety that is not used on a daily basis by and among Arabs, hence called 'an artificial variety' by Al-Batal himself (p.123). Palmer (2007) considers teaching this variety as a disservice to students calling for an expansion in teaching the spoken varieties to become the norm in these programs. Younes (1995), another keen advocate for teaching the spoken variety, says: 'if the goal of an Arabic-as-a-foreign-language program is to prepare students to function successfully in Arabic, then they should be introduced to both a Spoken Arabic dialect and [formal Arabic] from the beginning of an Arabic course (p.232).'

Palmer (2007) says that students who have studied only this high variety i.e. MSA 'are kept outside the in-groups' and often experience frustration and embarrassment when trying to communicate with Arabic speakers (p.112).' Moreover, he continues to say that often Arabs ridicule or make fun of foreigners speaking the formal language.

Palmer (2008) conducted an empirical study in which he surveyed the students' preferences regarding which variety to learn. He generally found that students prefer to learn a spoken variety of Arabic. Nevertheless, in addition to the limited number of respondents the study relies upon, he has not suggested any spoken variety to be taught or as the 
most suitable one.

Ryding (1995) says that although MSA has been enforced first and foremost in teaching while other dialects are disregarded, this is in fact taking place against the natural order of acquisition in which native speakers acquire the vernacular first. A claim that is seconded by Palmer (2007) who says that Arabic is taught in the United States in exactly the opposite way of acquiring language.

Al-Batal and Belnap (2006) state that an Arabic teaching classroom should reflect or mirror real life through having 'multiple registers. They (2006) have summarized the situation of Arabic teaching in the following paragraph:

Arabic teaching in the US began in philologically oriented departments that offered classical Arabic grammar and text-reading. With the updating of methodologies and a growth in interest in the modern Middle East, textbooks focused on what linguists termed Modern Standard Arabic. Spoken Arabic was taught separately, typically in transliteration. P.396.

But, one might ask why MSA is still taught first and foremost in most programs in the United States and why the dialects are still disregarded or partially ignored in the programs teaching Arabic in the states.

Some answers have been proposed by the scholars who advocate teaching the spoken varieties. Palmer (2007) says that spoken Arabic (a general term referring to a wide range of varieties) is not taught and researched on a large scale due to its low prestige. He further says that these varieties, according to their native speakers, are not deemed worthy of any linguistic attention or research. He points out that there is a common misconception in the Arab world that the spoken varieties are corruptions of MSA or classical Arabic (CA). In this respect, Versteegh (2004) says:

It remains difficult in the Arab world to arouse interest in the dialects as a serious object of study. Many speakers of Arabic still believe that the dialect is a variety of language without a grammar ..... and even in the universities there is a certain reluctance to accept dialect studies as a dissertation subject. (p. 132)

Palmer (2007) admits that there is a strong opposition for teaching spoken varieties solely or introducing spoken varieties earlier in the programs. Yet he suggests that students should be exposed to MSA as well as spoken Arabic to reach native or near native proficiency. He further claims that early exposure to spoken varieties of Arabic should become the norm in Arabic learning programs in the United States. Al-Batal and Belnap (2006), who are keen advocates of teaching spoken varieties at earlier stages, admit that this proposal is difficult due the following points (p. 396):

1. The impossibility of dealing with a full range of Arabic dialects; each country has its own general dialect which is itself a general umbrella for smaller regional varieties.

2. The difficulty of choosing a certain variety to teach.

3. $86 \%$ of the students who preferred leaning spoken Arabic prefer either Levantine or Egyptian Arabic, which means ignoring the other dialects.

Obviously, while scholars are calling for teaching the spoken variety at earlier stages or to be exposed to learners at the same time of introducing MSA, they admit that this task is very difficult for the various factors introduced above.

Modern standard Arabic, as can be seen from previous discussions, is all the time attached to and compared with the spoken varieties in a distinctive way that applies to a very restricted group of languages.

\section{Why MSA for Non-Native Speakers of Arabic?}

This section will introduce 12 different arguments or reasons supporting teaching MSA as the main language taught to students of Arabic as a foreign language. However I do not assume that the various varieties of spoken Arabic be disregarded. Rather, I think that students should be introduced to the phenomenon of diglossia and be exposed to excerpts or manifests from different dialects at a time. Students thus will be knowledgeable about diglossia and will realize the great variation witnessed between the dialects of spoken Arabic.

In the following paragraphs, I will propose 12 arguments - reasons, factors, motives - that support teaching MSA. The arguments and their headings are listed below:

1. MSA as a lingua Franca

2. Acquisition vs learning

3. MSA is mutually intelligible

4. MSA is the variety of nobody

5. Which Dialect to teach

6. Each spoken variety is a general term

7. Pride in speaking MSA

8. MSA is a path to convert to Islam

9. MSA paves the way for pursuing studies
Lingua franca.

Acquisition

Intelligibility.

Neutrality.

Selection.

Regional varieties.

Pride and respect.

Conversion

Pursue Students. 
10. Dialects are mostly not codified

11. Restricted to limited countries

12. Expressions across dialects may not
Codification.

Job/Career restriction.

Variation in meaning have the same meaning

\subsection{Lingua Franca:}

A lingua Franca is a language of wider of communication (Holmes: 2001). It is used by people who do not speak each other's languages. English nowadays is the universal lingua franca; we resort to English whenever we find ourselves in a situation where we do not speak or understand the other's language and the same applies to the other side. I assume that MSA can be viewed as a lingua franca to communicate with other Arabic speakers whose spoken varieties are not understood. Thus, MSA can be used as a lingua franca between non-native speakers of Arabic and native speakers of Arabic on the one hand, and between native speakers of different spoken Arabic varieties since it is generally speaking understood all over the Arab world. In this context, I will give a personal experience supporting this argument. When I was teaching Arabic in the United States, I was asked to accompany some American students to learn Arabic in Morocco.

When I arrived there, I found that I could barely understand Moroccan Arabic, and the students were not any much better. So we resorted to MSA which helped us overcome our first days there. Of course this obvious need for a lingua franca will be nullified after a certain period of time through which one gets accustomed to the new dialect. This obvious need to teach MSA does not mean ignoring exposing students to other spoken varieties in the Arab world.

This assumption can be strengthened when we view the close relationship between language and Islam. All Islamic rituals are performed through Standard Arabic; a fact that means that Standard Arabic is understood generally speaking by all the Arab Muslims around the world, and to a limited level by all non-Arab Muslims.

\subsection{Acquisition:}

As mentioned before, Ryding (1995) and Palmer (2007) say that Arabic teaching is taking place against the natural order of acquiring a language in which the vernacular is acquired at home and the standard is learned at school. Obviously, acquisition is different from learning. Acquisition takes place at really early stages in life and in a native atmosphere where a large group of people share the same chances of fluency or mastery of a language. Moreover, acquisition is subconscious where the learners are unaware of the grammatical rules. Acquisition takes place at home or in a situation in which one is exposed excessively and constantly to the language.

Learning, on the other hand, is a result of direct instruction of the rules of the language. It involves limited exposure to the rules of the language in organized, planned but fake or even- in its best situations- simi-real sessions. Learning is the conscious exposure to language rules.

Obviously, what we are doing in teaching MSA is the second process in which students are taught the rules of a language in organized classes. Finally, even if we adopted the approach suggested by scholars for teaching the vernacular first and foremost, we will not end up in students reaching the stage of fluency of nativity in the language since they are exposed to the language later than what is usually required to be native speakers of the language.

\subsection{Mutual Intelligibility:}

Unlike some spoken varieties of Arabic, MSA is comprehensible to nearly all the speakers of Arabic. Though they do not use it for daily conversations, Arabs are exposed daily to MSA in varying degrees: they read it in books, newspapers and advertisements, and they hear it spoken in news broadcasts, weather forecasts, various programs, religious gatherings, lectures, etc. The fluency of Arabic speakers and learners vary of course from one country to another and from one individual to another. Disregarding scientific, technical and specialized-oriented discussions which require a certain level of education or knowledge, nearly all the Arabic speakers- regardless of their gender, age, and level of education- and learners can be involved in basic conversations in which MSA is unidirectionally-(i.e. comprehesion) or bidirectionallyused (i.e speech and comprehension). In this respect, Palmer (2007) says that Modern Standard Arabic (MSA) is mutually intelligible throughout the Arab world since it is used in the media and in formal situations.

It is true that Arab children do not study MSA before they get into elementary schools; however, they are abundantly exposed to this variety very much earlier. They are usually told stories in MSA; they are taught prayers whether Islamic or Christian in MSA; they watch children programs in MSA and most of the cartoon shows are produced in MSA. In fact, all satellite Arabic channels directed to children including Spacetoon, MBC3, Baraem, Jeem, Ajial, CN Arabia use MSA. I think they do so to guarantee acceptability, neutrality, accessibility and comprehension. 
Another point that is related here is the one mentioned by palmer (2007) that native speakers of Arabic of any variety often snicker at foreigners who only speak MSA, 'thus potentially causing a sense of humiliation (p.112).' I think that his argument is not quite right. Speakers of other varieties of spoken Arabic or non-native Speakers of Arabic will not be snickered at when they use MSA; rather, they will be welcome and admired. Holmes $(2001,29)$ says that native Arabic speakers are impressed by foreigners who speak or master speaking CA or MSA. In fact, speakers of Arabic would snicker at members of the same community who try to communicate or speak in MSA only. Many are the times in which some members of newly-established groups especially Islamic or national ones which realized the importance of standard Arabic to the ideas of their groups have adopted MSA for their daily communication, in which case they were received with rebuke and snickering.

\subsection{Neutrality:}

MSA is still the variety of nobody and everybody at the same time. Nobody can claim that MSA is his or her native language; however, it is understood by nearly all the people in the Arab World. MSA does not carry any political or identity connotations; unlike national dialects which indicate attachment to a certain country since their names are derived from the name of the country thus there is Jordanian Arabic, Egyptian Arabic, ect. MSA can be viewed as culture-free; one can learn the language without worrying about the culture of Arabs since it is not used in daily life communication. Nevertheless, the spoken varieties are culture-bound; when the variety is learned, one needs to know some information about the people speaking that culture since not all Arabs are symmetrical in terms customs and traditions. In this context, Palmer (2007) says 'these spoken varieties differ more and more significantly from each other the further one goes from one's place of origin' (p.113). He further adds that each regional variety represents a unique culture that is different from the culture of other spoken varieties of Arabic. If a foreign learner of Arabic is heard talking Jordanian Arabic, one would guess that he or she has either studied in Jordan or taught by a Jordanian instructor in his or her home country.

The merit of MSA becomes evident at times when unfavorable political disturbances similar to what we see nowadays take place. Teaching one vernacular means that programs of study abroad will target the country of that vernacular; nevertheless, has anything unfavorable taken place in that country; a director or a person in charge will be forced to pull students from that country and in that case no other country will be able to teach that variety; thus, losing a long time preparation and planning. Moreover, teaching a certain vernacular or one spoken variety may mean allegiance to that variety or to the country in which the variety is used; a fact that may affect students' job opportunities, and political appearance.

\subsection{Selection:}

The question of determining which dialect or variety of spoken Arabic is a major concern in this respect. One might ask why a certain dialect is favored over other dialects. This question was stressed by Al-Balal and Belnap $(2006,396)$ when they say that it is difficult to choose one dialect to teach. They also say that (86\%) of students who expressed interest in learning spoken Arabic preferred either Levantine or Egyptian Arabic, which means that other dialects will disregarded or purposefully ignored. This also means abundance in open job positions for the instructors in these varieties and limited or no job opportunities for speakers of other varieties. Moreover, Palmer (2007) states that this heated discussion has led to no end, and scholars have begun to hope that such a discussion would be forsaken or stopped.

Above all, choosing a certain variety would require finding answers for the following questions: what are the criteria of choosing one variety and ignoring others? What are the merits of the chosen variety in comparison to other varieties? What are the job merits this variety would guarantee? How would this variety give the learner a better job opportunity?

Even if the multiple register approach suggested by Al-Batal and Belnap (2006) is adopted, we end up facing other problems. How can we have multiple registers if all the books focus on one or two dialects and the instructors are only proficient in their native dialects?

In fact, there are no objective criteria on basis of which a certain variety is chosen; a certain spoken variety is simply chosen because the instructor is a speaker of that variety, or because the institutes the students are enrolled at have signed an MOU with another institute in a country speaking the specified dialect.

\subsection{Regional Varieties:}

A national spoken variety e.g. Jordanian Arabic, Egyptian Arabic, etc is in fact a general label that involves several 
regional or social varieties or sub-dialects that are- though largely mutually intelligible- different. This variation is witnessed at different linguistic levels: phonetic, lexical, or syntactic and ranges from simple to large scale. This fact complicates the problem even more. Have we decided to teach a certain spoken variety, are we supposed to include all the different phonetic, lexical or structural variants found in the regional dialects? In case we decided not to mention these variants, which variety are we supposed to select? Zuraiq and Zhang (2007), for example, say that there are four subdialects of Jordanian Arabic that are evenly distributed in terms of population and status. The differences between these varieties are evident at all levels though not major ones. The four sub-dialects are:

a. Urban Jordanian Arabic

b. Ghorani Jordanian Arabic

c. Rural Jordanian Arabic

d. Bedouin Jordanian Arabic

Choosing one of these sub-dialects would mean neglecting all the other dialects, and one cannot integrate the four dialects in one since the result will be an unspoken variety besides the fact that this process is time and effort consuming.

Authors who have wrote books about the grammar of a national dialect or teaching a national dialect, must have chosen a certain variety since it is most likely the one used in the capital city of the country or because it is his native dialect, and at the same time asked to be excused from the speakers of other dialects for doing so.

\subsection{Pride and Respect:}

As a native speaker of Jordanian Arabic, I can say that a native speaker of a spoken variety of Arabic would be rebuked or become an example of ridicule when using MSA in domains of language use (Fishman, 1972) that require a spoken variety customarily used for this purpose. Such a person would be seen joking or playing around and would be termed or referred to by expressions that indicate his unusual use of language. Such expressions include "bitfas ${ }^{i}$ han" meaning "standardizing" or "using the standard", "bilwi bilsanu" meaning "twisting his tongue". Native speakers of Arabic regardless of their origins and the variety they usually use, would be pleased when they face or hear a non-native speaker of Arabic speaking their variety or MSA equally. In fact, they will be overwhelmed by pride when they hear a learner using MSA, and sometimes this situation may lead them to blame themselves for their insufficient efforts in learning MSA or protecting it or participating into spreading it.

Finally, when foreign language learners of Arabic are taught MSA, they are taught a prestigious variety that is considered so by its speakers and foreigners at the same footing. However, when they are taught a dialect, they are taught a variety that is humiliated and viewed low by its native speakers regardless of the variety.

\subsection{Convert:}

MSA is sometimes viewed by some educationalists and specialists specially those who have Islamic orientations as a path to convert the learners to Islam. They may do this through emphasizing the close connection between the Holy book, the Holy Quran and Prophet Mohammad's (peace be upon him) Hadiths (sayings) on the one side with Standard Arabic on the other since these two major Islamic sources are kept in Standard Arabic. Students may through the stages of their studies be introduced to various verses from The Holy Quran or various excerpts from the Hadiths of Prophet Mohammed (PBUH) being told that they should learn MSA intensively to understand these sources better. Although the cases of conversion to Islam are very sporadic, and are usually built on voluntary convention, students do belief, and this is a truism, that MSA is the only path to understand Islam as will be mentioned below.

\subsection{Pursue Studies:}

Learning MSA may open for learners new horizons in understanding the mysterious orient which have always allured the westerners along ages. Islam is considered in the eyes of westerners the core of mystery and the most alluring of all. Learners of MSA may be convinced to pursue some studies in Islam or to do some Quranic studies. Regardless of study motives, MSA would facilitate this issue since it will enable them- with some difficulty of course- to read the Quran, the various interpretations of the Quran, the Hadiths of prophet Mohammad (PBUH), some specialized books in the field and a rich literary heritage since all these are stored in Standard Arabic. These sources cannot be approached through any other variety. These texts are considered sacred and are expressed in a sacred and prestigious language. Moreover, most of these bookrs appeared in Standard Arabic a long time ago before the appearance of what we have nowadays 
what we call dialects.

Learning only a dialect or focusing on a dialect would not facilitate such a task; rather, it will make it more complicated since this means - had a person decided to do so - that he or she needs to start learning MSA as a key for such studies.

\subsection{Codification:}

Generally speaking, all varieties of spoken Arabic are vernacular varieties that are unwritten and unstandardised, in which case scholars in the field find themselves forced either to teach these varieties for listening and speaking skills forgetting about the other two skills, or to adopt new symbols to represent the sounds found in these spoken dialects and not found in MSA. For example, the sounds / $\mathrm{g} /$ as in 'game' and $/ \mathrm{t} / \mathrm{as}$ in 'church' are used in rural Jordanian Arabic while they are not found among the sound inventory of MSA. The scholar in the field has then two choices. They can solely teach the dialect in separation from MSA, adopting the writing symbols of MSA and creating some new symbols for the missing sounds which is a difficult job since the symbols are not standardized, or they can teach MSA solely as a written and read variety, exposing students to one or two of the varieties to show them the variation that might take place between the vernaculars on the one side and MSA on the other, and between the varieties themselves.

Teaching MSA would definitely mean giving the students access to large and respectable heritage of religious, literary, grammatical and linguistic sources expanding from the Pre-Islamic period to the moment. Focusing on one of the spoken varieties would prevent students from obtaining this rich academic experience.

\subsection{Career Restrictions:}

Exposing students to one of the dialects may restrict their access to the various job opportunities related to Arabic available in their home countries and in the Arab world. This supposedly and potentially means that non-native speakers of Arabic who were exposed to one variety or who have learned a certain variety, Jordanian Arabic (JA), for example, will not be chosen to a fill a position where Saudi Arabic, or Egyptian Arabic, or Sudanese Arabic or even Syrian Arabic, which is very close to JA, are suitable for three reasons. First: varieties as mentioned before vary minimally or maximally at all levels, though most will not reach the degree of unintelligibility. Second: as mentioned before, each variety is connected to a different culture. Third: it is implausible to select a Jordanian Arabic learner to fill a position in Egypt or in any other country while there are qualified competitors from the same country.

Closely related to this issue are the TV and radio political interviews that are taking place with non-native speakers of Arabic on a daily basis on the most influential TV and radio channels like Al-Jazeerah, Al-Arabiya, BBC and Monte Carlo. It is quite illogical to host a Russian or an American political figure to talk about the political situation in Syria using Jordanian Arabic or Egyptian Arabic. The situation would seem unconvincingly similar to asking from a mechanic to diagnose your disease symptoms. Using a certain variety may be sometimes taken to represent the political views of the country in which the variety is used towards certain issues.

Using MSA is seen the safest. It does not express any political orientation; it does not require certain job requirements but fluency, and it is understood everywhere in the Arab world.

\subsection{Variety in Meaning:}

The different spoken varieties in the Arab world differ significantly as one moves eastward or westward. Some of these varieties are mutually unintelligible. In this context, Watson (2002) proposes a truism about Arabic varieties by saying that these varieties may differ to a degree of mutual unintelligibility. Watson (2002) says:

Dialects of Arabic form a roughly continuous spectrum of variation, with dialects spoken in the eastern and the western extremes of the Arab-speaking world being mutually unintelligible. ( $p$ 8).

The different spoken varieties in the Arab world expose variation at various levels: phonetic, morphological, lexical, syntactic and semantic. Palmer (2007) writes 'spoken varieties of Arabic differ more and more significantly from each other the further one goes from one's place of origin.' He further shows in the table borrowed below how the sentence 'I want to go now.' is rendered differently in six varieties of Arabic including Standard Arabic.

Table (1): The realizations of "I want to go now" in six varieties of Arabic from Palmer (2007):

\begin{tabular}{|l|l|}
\hline The variety & I want to go now \\
\hline
\end{tabular}




\begin{tabular}{|l|l|}
\hline Iraqi Arabic & Areed aruuH haessa \\
\hline Syrian Arabic & Biddi ruuH haellae(q) \\
\hline Jordanian & Biddi aruuH haellae(q) \\
\hline Egyptian & Aawiz aruuH dilwa'ti \\
\hline Moroccan & Bgheet nimshi daaba \\
\hline MSA & Ureedu an ath-haba alaan \\
\hline
\end{tabular}

I can further add that any variety shows more variation than we could imagine. The term Jordanian Arabic, for example, is a general umbrella for a variety of different regional dialects. The sentence "I want to go now" can be realized in one of the following forms:

Biddr aru:h hallas Urban JA

Baddr aru:h hassa/? Northern J A

Baddı aru:h hal-hı:n Beduin JA.

Very recently Al-Jazeerah channel -an eminent name in the world of news, has started broadcasting a program about the Gulf area before the discovery of oil. Most of the interviewees were old men. However in the only episode I watched, the old man speech was not wholly intelligible to me or to other viewers, a fact which justifies Al-Jazeerah subtitling his speech into standard Arabic - and this is quite very often when the interviewees come from various regions especially, Algeria, Morocco, and Mauretania.

Related to this issue are the words used across the Arab world with different meanings; some of them are negative. Consider the following table that includes a list of words that have varied meanings in Jordanian and Moroccan Arabic, the two dialects I have been exposed to abundantly:

\begin{tabular}{|l|l|l|}
\hline The words & Jordanian Arabic & Moroccan Arabic \\
\hline Safjah & Health & Fire \\
\hline t $^{\mathrm{a} a b o: n}$ & Trunk of a car & The buttocks \\
\hline mloxija & Corchorus & Okra \\
\hline tomatoes & bandora & mat $^{\mathrm{S}}$ ifah \\
\hline Tea & Sar & ?atar \\
\hline
\end{tabular}

The table clearly shows that using the expression that is commonly used among Jordanian Allah jIIt $I$ : $k$ PI- Sa.fj Ih 'May Allah give you health' will be misunderstood by a Moroccan as a prayer to Allah to give him fire. In this context, I have to recount an anecdote that happened with me personally when I was in Morocco. I asked the waiter of a good restaurant whether they have falafel or not. He positively answered as yes. I asked for some. To my astonishment, he brought to me some roasted sweet peppers which are called in Jordanian Arabic and Moroccan with a word containing similar sounds. It is called felfel hilu meaning 'sweet peppers.' Falafel as we know it in the Middle East is not part of the Moroccan cuisine, and it has been very recently but narrowly introduced to the country, especially in the major cities.

\section{The Conclusion}

This paper proposes that teaching Modern Standard Arabic is still considered a great benefit for non-native speakers of Arabic. The paper calls for liberating MSA from the diglossic situation in which it is always captured in when compared to the spoken varieties. Further, it calls for teaching Arabic as a lingua france; as the most widely understood variety in the Arab world. By doing to, students are saved the burden of lexical and semantic complexity they may go through as result of learning a specific spoken variety and the aftermath of unpredictable political situations especially these days when the Arabic spring is spreading throughout various place in the Arab world. Teaching MSA will facilitate their access to the Arab world in general regardless of the motive whether it is career, study, tourism or any other reason. A certain spoken variety will be surely unwelcome in a country which is not its original one. Finally an empirical research in which students are simply asked a batch of guided question about their preferences regarding varieties does not give a clear indication of the preference if the learners are not given a panoramic view of the opportunities MSA will provide them in comparison to other varieties. These empirical studies are required to rely upon for future planning in the field.

\section{References}


Abuhamida, Z. (1988). Speech Diversity and Language Unity: Arabic as an integrating Factor. In Ciacomo Luciani and Ghassan Salam (eds.) The Politics of Arab integration, 25-42. London: Croom Helm.

Al-Batal, M (1995). Issues in the teaching the productive skills in Arabic. In M.

Al-Batal (Ed.) The teaching of Arabic as a foreign language: Issues and Directions. 115-133. Provo, Utah: American Association of Teachers of Arabic.

Al-Batal, M and Belnap, R. K. (2006). The teaching and learning of Arabic in the United States: Realities, needs, and future directions. In Kassan M. Wahba,

Zeinab A. Taha and Liz England. (Eds.) Handbook for Arabic language teaching professionals. 389-399. Mahwah, New Jersey: Lawrence Earlbaum.

Brustad, K., Al-Batal, M. and Al-Tonsi, A. (2004). Alkitab fi ta'alum al-'arabiya: A textbook for beginners. Washington DC: Georgetown University Press.

Ferguson, C. A., (1959). Diglossia. Word 15:325-340.

Ferguson, C. A., (1996). Sociolinguistic perspectives: Papers on language in society. 1959-1994. New York: Oxford University Press.

Fishman, J.A. (1972) The relationship between micro- and macro- sociolinguistics in the study of who speaks what language to whom and when. In Pride, J. B. and J. Holmes. (Eds.) Sociolinguistics: Selected readings. Middlesex: Penguin books.

Furman, N., David G., and Natalia L. (2010). Enrollments in languages other than English in United States institutions of Higher Education, Fall 2009.

Broadway, New York: Modern Language Association.

Haeri, N. (2003). Sacred language, Ordinary people. New York: Palgrave.

Holmes, J. (2001). An Introduction to Sociolinguistics. Harlow, Eng.; New York: Longman.

Palmer, J. 2007. Arabic diglossia: Teaching only the standard variety is a disservice to Students. Arizona Working Papers in SLA and Teaching. 14, 111-122.

Palmer, J (2008). Arabic diglossia: Student perception of spoken Arabic after living in the Arabic-speaking world. Arizona Working Papers in SLA and Teaching. 81-95.

Ryding, K. C. (1995). Discourse competence in TAFL: Skill levels and choice of language variety in Arabic classroom. In M. Al-Batal (Ed.) The Teaching of

Arabic as a foreign language: Issues and directions, 115-133. Provo, Utah: American Association of Teachers of Arabic.

Suleiman, Y. (2003). The Arabic language and national identity. Washington DC: Georgetown University Press.

Stadlbauer, S. (2010). Language ideologies in the Arabic diglossia of Egypt. Colorado Research in Linguistics. 22:1-19.

Van Moll, M. (2010). Variation in modern standard Arabic in radio news broadcasts: a synchronic descriptive investigation into the use of complementary particles. Leuven; Dudley: Mass. Peeters and Department Oostere Studies.

Versteegh, K. (2004). The Arabic language. Edinburgh: Edinburgh University Press.

Watson, J. C. E. (2002). The phonology and the morphology of Arabic. Oxford: Oxford University Press.

Welles, Elizabeth B. (2004). Foreign Language Enrollments in United States Institutions of Higher Education, Fall 2002. ADFL Bulletin. $34(2-3), 7-26$.

Younes, M. A. (1995). An Integrated Curriculum for elementary Arabic. In M. Al-Batal (Ed.) The teaching of Arabic as a foreign language: issues and directions. pp233-255. Provo, Utah: American Association of Teachers of Arabic.

Zuraiq, W. and Jie Z.. (2007). Phonological Assimilation in Urban Jordanian Arabic. Kansas Working Papers in Linguistics 28, 33-64. 